\title{
Primary care contact prior to suicide in individuals with mental illness
}

\author{
Anna Pearson, Pooja Saini, Damian Da Cruz, Caroline Miles, David While, \\ Nicola Swinson, Alyson Williams, Jenny Shaw, Louis Appleby, and Navneet Kapur
}

\begin{abstract}
\section{Background}

Previous studies have reported differing rates of consultation with GPs prior to suicide. Patients with a psychiatric history have higher rates of consultation and consult closer to the time of their death.

Aim

To investigate the frequency and nature of general practice consultations in the year before suicide for patients in current, or recent, contact with secondary mental health services.
\end{abstract}

\section{Design of study}

Retrospective case-note study and semi-structured interviews.

\section{Setting}

General practices in the northwest of England.

\section{Method}

General practice data were obtained by a retrospective review of medical records $(n=247)$ and semistructured interviews with GPs $(n=159)$.

\section{Results}

GP records were reviewed in 247 of the 286 cases (86\%). Overall, $91 \%$ of individuals $(n=224)$ consulted their GP on at least one occasion in the year before death. The median number of consultations was 7 (interquartile range $=3-10$ ). Interviews were carried out with GPs with regard to 159 patients. GPs reported concerns about their patient's safety in $43(27 \%)$ cases, but only $16 \%$ of them thought that the suicide could have been prevented. Agreement between GPs and mental health teams regarding risk of suicide was poor. Both sets of clinicians rated moderate to high levels of risk in only $3 \%$ of cases for whom information was available $(n=139)$ (overall $\kappa=0.024)$.

\section{Conclusion}

Consultation prior to suicide is common but suicide prevention in primary care is challenging. Possible strategies might include examining the potential benefits of risk assessment and collaborative working between primary and secondary care.

\section{Keywords}

general practice; mental health services; risk assessment; suicide.

\section{INTRODUCTION}

The reported proportion of individuals who have consulted GPs in the month prior to suicide has varied between $20 \%$ and $76 \% .^{1,2}$ Low rates of consultation have been recorded in those aged $<35$ years $^{3}$ and high rates in those aged $>60$ years. ${ }^{4-6}$ Those with a history of contact with mental health services have been shown to consult their GP closer to the time of suicide compared with those without such contact - studies have reported that half of these individuals consulted their GP in the month before death and a quarter in the week before death. ${ }^{3,7}$ Similarly, studies have found that those who die by suicide are significantly more likely to have xreceived a mental health diagnosis (of depression, anxiety, and alcoholism in particular) and to consult their GP more frequently than age- and sex-matched living controls. ${ }^{8}$

With regard to the communication of suicidal intent, one study reported that $31 \%$ of individuals who died by suicide discussed such thoughts or plans in consultations with their GPs, but that practitioners felt $42 \%$ were at increased risk. ${ }^{9}$ Figures for communicating suicidal intentions at the final GP

A Pearson, PhD, research associate; $P$ Saini; $M S c$, research assistant; D Da Cruz, MSc, research assistant; D While, PhD, research fellow; N Swinson, BSc, FRCPsych, consultant forensic psychiatrist; $\boldsymbol{A}$ Williams, $P h D$, deputy project manager at the Inquiry; J Shaw, FRCPsych, professor of forensic psychiatry \& assistant director of the Inquiry; L Appleby, MD, FRCPsych, director of the Inquiry \& national director for Mental Health England; N Kapur, MD, FRCPsych, professor of psychiatry and population health \& assistant director of the Inquiry, University of Manchester, Centre for Suicide Prevention, Manchester. C Miles, PhD, lecturer in criminology, University of Chester, Department of Social and Communications Studies, Chester.

Address for correspondence

Anna Pearson, Research Associate, University of Manchester, Centre for Suicide Prevention, Jean McFarlane Building, Oxford Road, Manchester, M13 9PL.

E-mail: anna.m.pearson@manchester.ac.uk

Submitted: 31 March 2009; Editor's response: 15 May 2009; final acceptance: 13 August 2009.

(c)British Journal of General Practice 2009; 59: 825-832.

DOI: 10.3399/bjgp09X472881 


\section{How this fits in}

Previous research has reported high rates of consultation with GPs prior to suicide and has raised concerns about the low levels of risk assessment. In the present study, the average rate of GP consultations in the year before death for those in current, or recent, contact with mental health services was high. However, only a minority (just over a quarter) of GPs reported concerns about their patient's safety at the final consultation and only a sixth thought that the suicide could have been prevented. In terms of risk assessment, agreement between primary and secondary care clinicians was poor. Future research and prevention strategies might examine ways of improving health professionals' identification of suicide risk and improving collaborative working between primary and secondary healthcare services. The impact of any initiatives on suicide rates and suicidal behaviour should also be measured.

consultation have varied. ${ }^{7,10}$ One study reported that the majority of those communicating suicidal intent also had a history of contact with psychiatric services. ${ }^{\top}$

Mental illness is known to be an important risk factor for suicide. In 2004 there were 4883 suicides in England and Wales, 27\% of which were by people who had been in contact with mental health services in the year before their death. ${ }^{11}$ Previous research examining primary care consultations before suicide in those with a psychiatric history has used comparatively small samples ${ }^{3-5,8}$ and has not considered the role of individual mental health diagnoses. ${ }^{3-7}$

The National Confidential Inquiry into Suicide and Homicide by People with Mental Illness (Inquiry) collects detailed clinical information from secondary mental health services on a national sample of suicides by people in current, or recent (within the previous 12 months), contact with such services. This study reports the results of an extension to Inquiry data collection for a sub-sample of patients to include detailed information from GPs in order to examine patterns of attendance in primary care with a view to informing prevention. The specific aims of the study were to:

- examine patterns of attendance at general practice in the year before death for a comprehensive sample of Inquiry cases;

- examine rates of consultation at primary care by mental health diagnosis;

- compare the characteristics of those with no or low levels of GP consultations with those who attended more frequently; and

- examine in detail the final general practice consultation before death.

\section{METHOD}

Sample

The methodology employed by the Inquiry has been described in detail elsewhere ${ }^{11-13}$ but, in short, information on all general population suicides and deaths from undetermined external causes is obtained from the Office for National Statistics. Mental health services identify those people in contact with services in the 12 months before death. Clinical data on these patients is then obtained through questionnaires sent to consultant psychiatrists. The Inquiry, therefore, provides a UK-wide case series of all suicides by people in mental health service contact in the year prior to death. The ascertainment procedures are robust and the response rate for questionnaire data is more than 95\%, which reflects the Inquiry's longstanding relationship with mental health professionals nationally. ${ }^{11}$

The sample for this study included people residing in the northwest of England, who had been in contact with mental health services and had died by suicide between January 2003 and December 2005. This area consisted of three strategic health authorities (Cheshire \& Merseyside, Greater Manchester, and Lancashire), which merged in 2006 to form NHS North West and had an estimated population of $6853200 .^{14}$

\section{Measures}

The Inquiry database was used to obtain baseline demographic and clinical data. General practice data were obtained by retrospective reviews of primary care medical records, both written and electronic. Where possible, semi-structured interviews were conducted with consenting GPs. The medical records questionnaire and interview schedule were adapted from tools used in previous research. ${ }^{11,12,15,16}$ Information was obtained on the patient's physical and mental health problems, consultations in the year before death, details of the final consultation, and views on prevention. Case-record reviews took approximately 1 hour and interviews generally lasted between 20 and 40 minutes. All interviews and most case-record reviews took place in the GPs' surgeries, but some records were viewed at primary care trust premises. Interviews were recorded if participating GPs consented to this.

\section{Analysis}

Data analyses were conducted using SPSS for Windows (version 15). Both parametric and nonparametric statistical tests were carried out when appropriate. These included the $\chi^{2}$ test of association, Fisher's exact test, analysis of variance, Duncan's multiple range test, Mann-Whitney $U$ test and the Kruskal-Wallis test. ${ }^{17}$ When percentages are quoted these refer to 'valid cases' (that is, cases for whom the relevant information were available); as a result the denominator varies between items. With respect 
to the interviews, much of the data were presented as simple frequencies. An inductive approach to the interview data was also used, utilising framework analysis to identify key themes ( $P$ Saini et al, unpublished data, 2009).

\section{RESULTS}

During the study period a total of 286 individuals in northwest England committed suicide within 12 months of contact with mental health services. GP records were reviewed in 247 (86\%) cases. Baseline characteristics of the patients are given in Table 1. In terms of sex, age, civil status, living circumstances, employment status, and clinical characteristics no significant differences were noted between the patients for whom GP data were obtained and those for whom it was not $(n=39)$.

\section{Case-note data}

GP attendance in the year prior to suicide. Figure 1 illustrates the total number of GP consultations in the year prior to death. Most individuals ( $n=224,91 \%)$ had at least one face-to-face consultation during this time, with the mean number of attendances being 8.3 (median $=7$, interquartile range [IQR] 3-10). Fisher's exact and $\chi^{2}$ tests were conducted to see if there were any significant differences between those who did, and did not, consult. No significant differences were observed in terms of sex, age, subject to enhanced aftercare (care programme approach), and missed last mental health contact.

Frequency of consultations. Figures for the average number of consultations in the year before suicide by primary mental health diagnosis are provided in Table 2. Both the one-way ANOVA and Kruskal-Wallis tests revealed significant differences, with those diagnosed with schizophrenia recording the lowest number of consultations and those diagnosed with other disorders (for example, dementia and organic disorders) or depressive illness/anxiety disorders the most. A Duncan's multiple range test found these three diagnostic groups to be homogenous subsets.

In 47 (21\%) cases at least one consultation resulted from previous non-fatal suicidal behaviour or selfharm. ${ }^{18,19} \mathrm{~A}$ further analysis based on past history of suicidal behaviour revealed no significant differences in the mean number of consultations for those with, and without, a history of self-harm.

The sample was divided into frequent consulters ( $\geq 6$ consultations, $n=123,50 \%$ ) and less frequent consulters $(0-5$ consultations in the year prior to death, $n=124,50 \%)$. Few significant differences were observed, but those who consulted frequently tended to be older than those who did not (median age 51 years [IQR $=39-61$ years] versus median age
Table 1. Baseline characteristics of the 247 patients who committed suicide and whose medical records were reviewed. ${ }^{a}$

\begin{tabular}{|c|c|c|c|}
\hline Characteristic & $n$ & $\%$ & $95 \% \mathrm{Cl}$ \\
\hline \multicolumn{4}{|l|}{$\operatorname{Sex}(n=247)$} \\
\hline Male & 16 & 68 & 62 to 73 \\
\hline Female & 80 & 32 & 27 to 38 \\
\hline \multicolumn{4}{|l|}{ Age, years $(n=247)$} \\
\hline$<35$ & 60 & 24 & 19 to 30 \\
\hline$\geq 35-46$ & 63 & 26 & 20 to 31 \\
\hline$\geq 46-57$ & 59 & 24 & 19 to 29 \\
\hline$\geq 57$ & 65 & 26 & 21 to 32 \\
\hline \multicolumn{4}{|l|}{ Primary diagnosis $(n=245)$} \\
\hline Schizophrenia/other delusional disorders & 50 & 20 & 15 to 25 \\
\hline Bipolar affective disorder & 16 & 7 & 3 to 10 \\
\hline Depressive illness and anxiety disorders & 104 & 42 & 36 to 49 \\
\hline Drug/alcohol dependence & 30 & 12 & 8 to 16 \\
\hline Personality disorders/adjustment disorders & 31 & 13 & 8 to 17 \\
\hline Other (for example, dementia, organic disorders) & 14 & 6 & 3 to 9 \\
\hline \multicolumn{4}{|l|}{ Method of suicide $(n=245)$} \\
\hline Self-poisoning & 79 & 32 & 26 to 38 \\
\hline Carbon monoxide poisoning & 9 & 4 & 1 to 6 \\
\hline Hanging & 89 & 36 & 30 to 42 \\
\hline Drowning & 17 & 7 & 4 to 10 \\
\hline Jumping (for example, from height, in front of moving object) & 31 & 13 & 8 to 17 \\
\hline Other (for example, firearms cutting, burning, suffocation) & 20 & 8 & 5 to 12 \\
\hline \multicolumn{4}{|l|}{ Clinical characteristics } \\
\hline \multicolumn{4}{|l|}{ History of deliberate self-harm $(n=236)$} \\
\hline Yes & 174 & 74 & 68 to 79 \\
\hline No & 62 & 26 & 21 to 32 \\
\hline \multicolumn{4}{|l|}{ Subject to enhanced aftercare, CPA $(n=237)$} \\
\hline Yes & 96 & 41 & 34 to 47 \\
\hline No & 141 & 59 & 53 to 66 \\
\hline \multicolumn{4}{|l|}{ Missed last mental health appointment $(n=211)$} \\
\hline Yes & 57 & 27 & 21 to 33 \\
\hline No & 154 & 73 & 67 to 79 \\
\hline \multicolumn{4}{|l|}{ Non-compliant with medication $(n=220)$} \\
\hline Yes & 39 & 18 & 13 to 23 \\
\hline No & 181 & 82 & 77 to 87 \\
\hline
\end{tabular}

${ }^{a}$ Baseline information from National Confidential Inquiry database. CPA = care programme approach.

42 years, [IQR $=33-53$ years]), Mann-Whitney $U=$ 5742.500, $P=0.001$ ). A significant association with living circumstances was evident. Of those living with a spouse or partner, $43(61 \%)$ were frequent consulters, whereas only 10 (24\%) of those living with their parents or children were frequent consulters $\left(\chi^{2}=\right.$ 16.482, degrees of freedom [df] $=3, P=0.001$ ). Where known (228 cases) the figures for living circumstances for the cases where medical records were reviewed were: alone $n=99,43 \%$; with spouse/partner (with or without children) $n=70,31 \%$; with family (parents or children) $n=42,18 \%$; and other (other shared, residential, or prison) $n=17,8 \%$.

Timing and reason for final consultation. The final GP consultations were examined in more detail and the timings of these are presented in Figure 2. The 
Figure 1. Total number of GP consultations in the 12 months before death ( $n=247)$. final GP consultation and death $(\mathrm{n}=224)$.
Figure 2. Time between

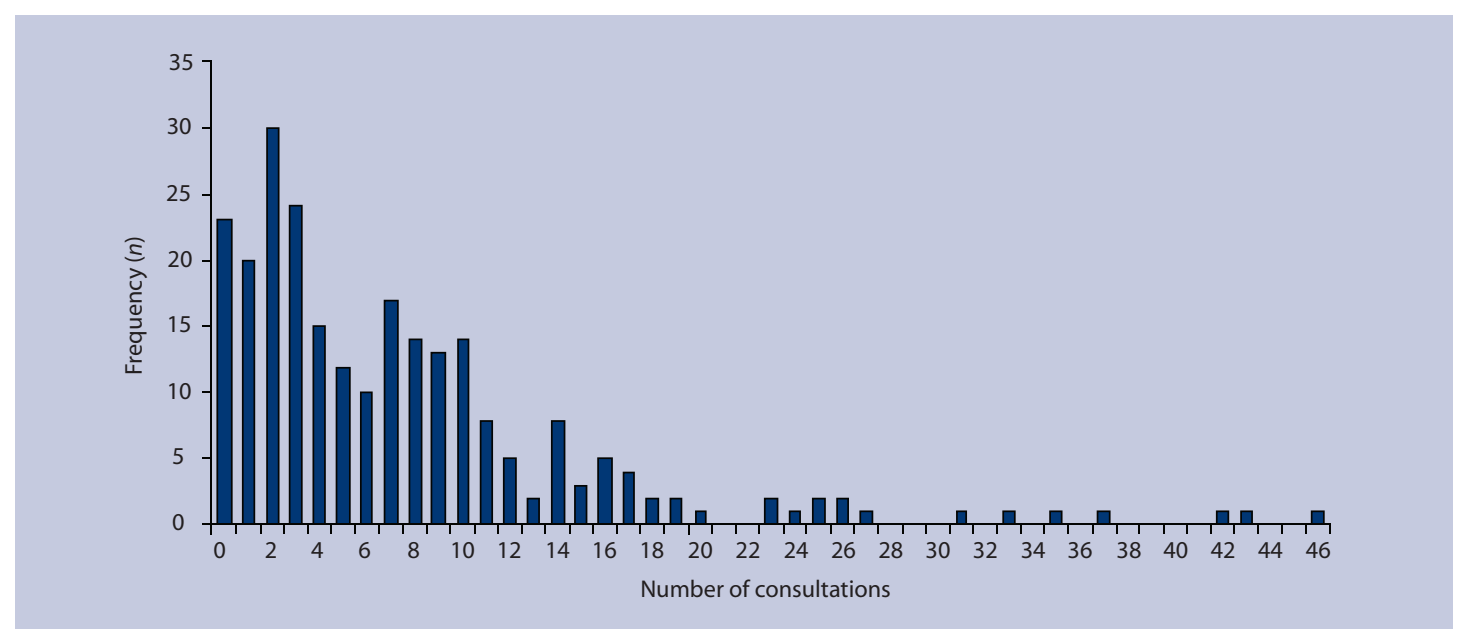

Table 2. Number of GP consultations in the year before suicide for those who were in contact by primary diagnosis.

\begin{tabular}{lccccc} 
Primary diagnosis & $n$ & Mean (95\% Cl) & Median (IQR) & Min & Max \\
\hline Schizophrenia/delusional disorders & 43 & $4.6(3.4$ to 5.8$)$ & $3(2.0-7.0)$ & 1 & 15 \\
Bipolar affective disorder & 16 & $6.9(4.3$ to 9.5$)$ & $6.5(2.0-10.0)$ & 1 & 17 \\
Depressive illness/anxiety disorders & 98 & $9.7(8.0$ to 11.4$)$ & $7(3.8-12.3)$ & 1 & 43 \\
Drug/alcohol dependence & 25 & $8.2(5.7$ to 10.7$)$ & $7(3.0-11.0)$ & 1 & 23 \\
Personality/adjustment disorders & 28 & $9.2(5.5$ to 12.9$)$ & $5.5(3.0-10.5)$ & 1 & 37 \\
Other (dementia/organic disorders) & 12 & $10.4(2.9$ to 18.0$)$ & $8(4.0-10.5)$ & 1 & 46 \\
\hline Total & 222 & $8.3(7.3$ to 9.3$)$ & $7(3.0-10.0)$ & 1 & 46 \\
\hline
\end{tabular}

ANOVA: sum of square $=895.039, d f=5$, mean square $=179.008, F=2.995, d f=5, \mathrm{P}=0.012$. Kruskal-Wallis: $\chi^{2}=18.597, d f$ $=5, \mathrm{P}=0.002 . d f=$ degrees of freedom. $I Q R=$ interquartile range. majority of the sample who did consult within 12 months of death had their final consultation within 6 months of their death $(n=204,91 \%)$. A total of 105 people $(47 \%)$ were seen in the month before death and $76(34 \%)$ of these were also seen by mental health services during this time. Given the results of the frequency of consultation by primary diagnosis, it was not surprising to find that more than half of those with depressive illness/anxiety disorders $(n=58,59 \%)$ and only a quarter of those with schizophrenia $(n=11$, $26 \%$ ) had their final GP consultation less than a month

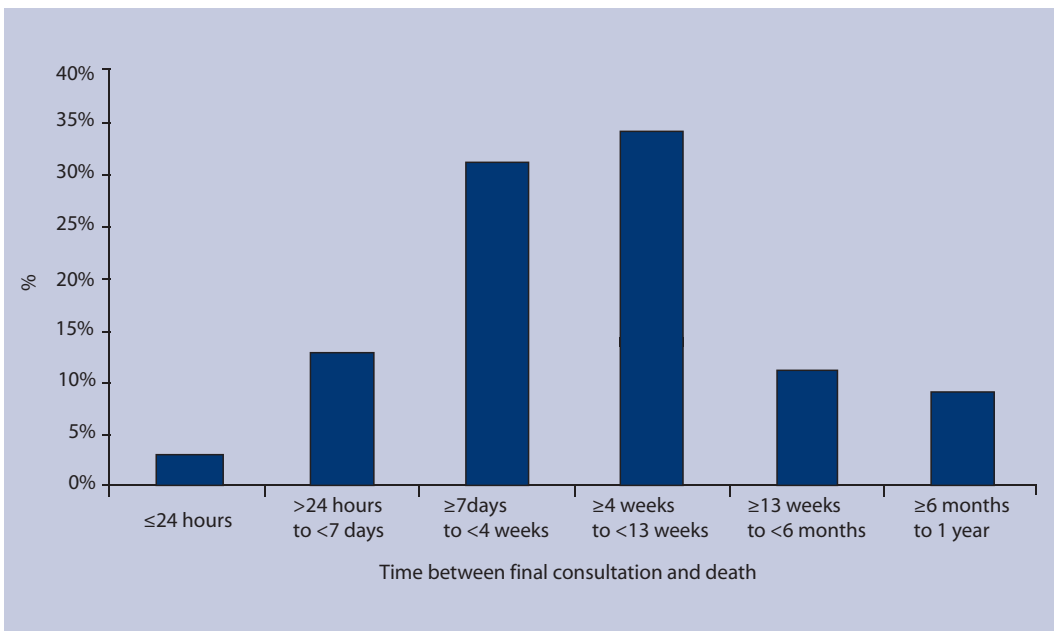

before their death $\left(\chi^{2}=14.558, \mathrm{df}=5, P=0.012\right)$.

In over half of the cases reviewed, the primary reason for the final consultation recorded in the notes was psychological symptoms $(n=122,54 \%) ; 52$ (23\%) were primarily for physical health reasons and $36(16 \%)$ for both psychological and physical health needs. No relationship was observed between the reason for final consultation and whether this consultation occurred within the month before death $\left(\chi^{2}=0.608, \mathrm{df}=2, P=0.739\right)$.

\section{Interview data}

In total 159 semi-structured interviews were carried out, representing $64 \%$ of those for whom the study had primary care case note data $(n=247)$. Comparison of baseline characteristics of those for whom the study did, and did not, have GP interview data revealed no significant differences in terms of sex, age, civil status, living circumstances, employment status, primary mental health diagnosis, method of suicide, and clinical characteristics.

Suicidal thoughts at final consultation. In interviews, 23/159 GPs (15\%) reported that their patient had expressed suicidal thoughts or intentions during their final consultation; however, no significant difference was observed in the timing of this consultation (final 
Table 3. Number of GP consultations in the year before suicide for those who were in contact by concern for patient safety at final consultation.

\begin{tabular}{lccccc} 
Concern for patient safety at final consultation & $n$ & Mean (95\% Cl) & Median (IQR) & Min & Max \\
\hline No & 109 & $8.0(6.6$ to 9.5$)$ & $7(2.5-10.0)$ & 1 & 42 \\
Yes & 42 & $11.6(8.1$ to 15.0$)$ & $8(3.0-16.5)$ & 1 & 46 \\
\hline Total & 151 & $9.0(7.6$ to 10.4$)$ & $7(3.0-11.0)$ & 1 & 46 \\
\hline
\end{tabular}

ANOVA: sum of square $=377.632, d f=1$, mean square $=377.632, F=5.000, \mathrm{P}=0.027$. Kruskal-Wallis: $\chi^{2}=3.445, d f=1$,

$\mathrm{P}=0.063 . d f=$ degrees of freedom. $I Q R=$ interquartile range.

consultation $<1$ month before death, $n=13[57 \%]$, versus final consultation $\geq 1$ month before death, $n=$ $10[44 \%])$.

Concern for patient safety at final consultation. Fortytwo $(42 / 159,26 \%)$ GPs stated in interviews that they were concerned for their patient's safety during the final consultation. The mean number of GP consultations in the year before suicide was significantly higher for those patients for whom the GP reported having concerns about their safety (Table 3 ). Additionally, where GPs had reported concerns, the patient was significantly more likely to have had their final consultation within the month before death (final consultation $<1$ month before death $n=26$ [62\%], versus final consultation $\geq 1$ month before death $n=16$ [38\%], $2=5.289, \mathrm{df}=1, P=0.021$ ).

In 27 (64\%) cases where GPs reported being concerned, they reported contacting mental health services to discuss and refer their patients for further assessment or treatment. In most of these cases the patients were assessed and some were admitted to hospital. However, two GPs reported that their referrals were not acted upon; in both cases the patients died within 2 weeks of their final GP consultation. An additional four (10\%) GPs offered referrals but they were declined by the patients. In two cases the GPs did not elaborate on the reason for the referral being declined, in the others the GPs stated that both the patients and their families did not want an admission to hospital.

Risk. GPs' concern for their patient's safety was also compared with Inquiry data regarding the level of risk of suicide perceived at final mental health service consultation by the mental health teams completing the general Inquiry questionnaire (Table 4). The study had both sets of assessments for 139 cases, so this was the denominator for these analyses. These results should be interpreted cautiously because the primary care and mental health assessments may have been carried out some time apart. In 91 (65\%) cases there was agreement between GPs and mental health teams that the patient presented little or no risk during their final consultation. Moderate to high levels of risk were identified more often by GPs. However, there were only four (3\%) cases where both sets of clinicians were concerned for the patient's safety or rated their level of risk as moderate to high (overall $\kappa$ $=0.024$, strength of agreement $=$ poor).

Prevention. Only 26/159 GPs (16\%) reported in interview that they felt that the suicide could have been prevented; 60 (38\%) thought that it could not, and the remaining $73(46 \%)$ were unsure. No association was observed between views on preventability and whether the final consultation was within the month before death $\left(\chi^{2}=0.056, \mathrm{df}=1, P=\right.$ 0.813).

When asked to elaborate on how GPs thought the death could have been prevented several key themes emerged. Improving access to services was identified as being important with some GPs reporting a lack of appropriate services, while others highlighted the delays their patients had experienced when being referred to services, or difficulties in admitting patients where the GPs thought that this was appropriate. GPs also suggested the need to improve information sharing between services, particularly with regard to their being provided with information about discharges or changes in risk promptly. GPs also commented on the need to improve the quality of monitoring and follow-up of patients both in hospital and in the community, especially in cases where patients had absconded from hospital or were failing to attend appointments.

Table 4. Risk at final consultation perceived by GPs and mental health teams.

\begin{tabular}{lcccc} 
& $\begin{array}{c}\text { GP concern for } \\
\text { patient safety }- \text { no }\end{array}$ & $\begin{array}{c}\text { GP concern for } \\
\text { patient safety }- \text { yes }\end{array}$ & Total \\
\hline Mental health team rated no/low risk & 91 & 36 & 127 \\
\hline Mental health team rated moderate/high risk & 8 & 4 & 12 \\
\hline Total & 99 & 40 & 139 \\
\hline
\end{tabular}




\section{DISCUSSION}

\section{Summary of the main findings}

The majority of patients in this study were seen by their GP on at least one occasion in the year before death and the average rate of attendance for this time period was high. Those with depressive illness/anxiety disorders or other disorders (organic/dementia) tended to consult more frequently than individuals with other diagnoses; the high consultation in the group with organic disorders/dementia could perhaps reflect the burden of physical morbidity). Almost half of all patients had their final GP consultation in the month before death and one-sixth in the week before death. Just over one-quarter of GPs reported being concerned for their patient's safety and one-sixth reported that their patient had expressed suicidal thoughts at final consultation. However, GPs and mental health services were not always in agreement about the level of risk present at final consultation. One-sixth of GPs stated that they thought the suicide could have been prevented.

\section{Strengths and limitations of the study}

One limitation to this study was that records based data were used. Previous research has highlighted methodological limitations in the use of medical record reviews, including variations in accuracy or the amount of detail provided ${ }^{20}$ and the risk of underestimating figures for consultations as not all are recorded in case notes. ${ }^{7}$ However, one study comparing GP records and patient self-report questionnaires found similar figures for the mean number of consultations in both sources. ${ }^{20}$ Additionally, a systematic review into computerised medical records revealed that the quality of the recording of consultations on such systems tended to be high. ${ }^{21}$

The response rate for case record reviews was $86 \%$. However, interview data was obtained on only $64 \%$ of those for whom the study had case records. In some cases GP interview data was unavailable as the GP had retired or died; others declined to be interviewed, often citing pressures of time. It is possible that some GPs may have been concerned about their assessment of suicidal risk; this may have introduced a selection bias. However, where the study was able to compare the baseline characteristics of those for whom it did, and did not, have case-record data and for those for whom it did, and did not, have GP interview data there were no differences between the groups.

This was a retrospective study and interviews may have been subject to recall bias, although this is unlikely to have had a significant impact on the medical records data. However, the sample consisted of suicides in current, or recent, contact with mental health services from the northwest of England and no comparison group of those who did not die by suicide was included. As such, the results may not be generalisable to other regions or individuals who died by suicide and did not have contact with mental health services and the study is unable to draw firm aetiological conclusions.

\section{Comparison with existing literature}

According to the Office for National Statistics' General Household Survey ${ }^{22}$ in 2007, $13 \%$ of adults and children (15\% females and $11 \%$ males) consulted an NHS GP in the 14 days prior to interview; this has remained relatively consistent for the past 30 years. The survey also reported that the average number of consultations for 2007 was four (five for females and four for males), with the majority occurring at a GP surgery (88\%).

Previously reported figures for the number of people consulting their GP in the year before suicide in general population samples have ranged from $57 \%$ to $90 \%{ }^{1,7,23}$ In the present study, of those in contact with mental health services, $91 \%$ had consulted their GP on at least one occasion in the year before suicide. In terms of consultation in the month and week before suicide the figures found in this research (month before $47 \%$, week before $16 \%$ ) are similar to previous studies of those not under the care of secondary mental health serivces. ${ }^{3,723}$ However, recent contact with patients (within a year of death) who go on to die by suicide is still relatively rare for GPs. ${ }^{7,2,24}$ For example, it has been estimated that, 'In an average list size of 1000 it will take 8 years of consultations before a GP will consult a patient who will shortly thereafter commit suicide. ${ }^{24}$

In this study the mean number of GP consultations in the year before death was 8.3 and even higher rates of consultation were recorded for those diagnosed with organic disorders/dementia and depressive illness/anxiety disorders. This is higher than rates of consultation in a previous study of individuals with and without psychiatric histories who died by suicide. ${ }^{8}$ The lower rates of GP contact for those diagnosed with schizophrenia observed in this study may reflect the fact that mental health services take a more active role in providing treatment for this group or that such individuals are reluctant to seek health care. A lower rate of attendance among younger people was observed in this study. A recent qualitative study found that many young adults held negative views about GPs as a source of support for mental health problems. ${ }^{25}$

For a fifth of the sample at least one consultation had been as a result of a previous act of self-harm or a suicide attempt, however, the communication of suicidal intent at the final consultation was only reported for $15 \%$ of patients. The corresponding figure in previous studies has ranged from $3 \%$ to $31 \% .{ }^{7,9,10}$ When asked for their views on how the 
suicides that took place could have been prevented GPs identified several problems including access to services, communication between primary and secondary services, and monitoring of both in- and outpatients, particularly those failing to attend appointments, all of which have been identified as problematic in the past. ${ }^{26-28}$

\section{Implications for future research and clinical practice}

All patients in this study were in contact with mental health services in the year before their death and, clearly, mental health services have an important role to play in preventing the suicide of such patients. There are a number of ways in which this might be done. ${ }^{11}$ Most individuals in this study continued to consult their GP in the year before death, some on a frequent basis, and some shortly before their death. This may represent an additional opportunity for prevention. However suicide prevention in primary care is a challenging task.

Of particular importance is the recognition of risk. In this study many patients had a history of non-fatal suicidal behaviour and some GPs reported patients expressing suicidal ideation during the final consultation. However, only a minority of GPs expressed concerns regarding their patient's safety. This may reflect the retrospective nature of the study, the actual (low) risk at the time of assessment, or an underestimation of risk. The assessment of risk is difficult. Previous research has raised concerns about the lack of risk assessment for suicide in primary care settings. ${ }^{29-31}$

It is interesting that GPs appeared more willing to acknowledge risk than the specialist mental health services in this study and that the level of agreement between these groups regarding risk was poor; as stated earlier, however, these results should be interpreted with some caution. The whole area of risk assessment, particularly the process and methods of assessment, would benefit from further research.

Recent research has commented on the need to improve medical student education in suicide prevention, including diagnostic interviewing skills, and has found both students and GPs to be supportive of a suicide-prevention curriculum. ${ }^{32-34}$ However, evidence for the efficacy of educational initiatives in the prevention of suicide has been mixed. ${ }^{35-37}$

In light of the views on prevention expressed by some GPs in this study it may be advantageous to develop strategies to improve multidisciplinary working and communication between secondary mental health services and primary care. For example, standards have been agreed within the NHS contract to reduce the length of time taken for hospitals to provide discharge summaries to GPs (in
April 2010 summaries should be provided within 24 hours of discharge). ${ }^{27}$ Additionally, evidence from primary research (much of it carried out in the US) suggests that the collaborative care model has been effective in improving patient outcomes. ${ }^{38}$ The impact of any such initiatives on suicide rates and suicidal behaviour should be carefully assessed in order to inform future prevention strategies.

\section{Funding body}

National Patient Safety Agency (MREC02/8/74)

\section{Ethics committee}

North West Multi-centre Research Ethics Committee (02/8/74)

\section{Competing interests}

Louis Appleby is the National Director for Mental Health, England. Navneet Kapur is Chair of the Guideline Development Group for the new NICE guidelines on self-harm

\section{Acknowledgements}

We thank all participating GPs and the primary care trusts that allowed access to medical records and participated in interviews. The study was carried out as part of the National Confidential Inquiry into Suicide and Homicide by People with Mental Illness. We thank the other members of the research team: Kirsten Windfuhr, Harriet Bickley, Jimmy Burns, Isabelle Hunt, Rebecca Lowe, Phil Stones, Pauline Turnbull, Sandra Flynn, Cathy Rodway, Alison Roscoe, and Kelly Hadfield. We acknowledge the help of health authorities and trust contacts and consultant psychiatrists for completing the questionnaires.

\section{Discuss this article}

Contribute and read comments about this article on the Discussion Forum: http://www.rcgp.org.uk/bjgp-discuss

\section{REFERENCES}

1. Luoma JB, Martin CE, Pearson JL. Contact with mental health and primary care providers before suicide: a review of the evidence. Am J Psychiatry 2002; 159(6): 909-916.

2. Pirkis J, Burgess P. Suicide and recency of health care contacts. A systematic review. Br J Psychiatry 1998; 173: 462-474.

3. Vassilas CA, Morgan HG. General practitioners' contact with victims of suicide. BMJ 1993; 307(6899): 300-301.

4. Vassilas CA, Morgan HG. Elderly suicides' contact with their general practitioner before death. Int J Geriatr Psychiatry 1994; 9: 1008-1009.

5. Harwood DMJ, Hawton K, Hope T, Jacoby R. Suicide in older people: mode of death, demographic factors and medical contact before death. Int J Geriatr Psychiatry 2000; 15(8): 736-743.

6. Tadros G, Salib E. Elderly suicide in primary care. Int J Geriatr Psychiatry 2007; 22(8): 750-756.

7. Matthews K, Milne S, Ashcroft GW. Role of doctors in the prevention of suicide: the final consultation. Br J Gen Pract 1994; 44(385): 345-348.

8. Power K, Davies C, Swanson V, et al. Case-control study of GP attendance rates by suicides with or without a psychiatric history. $\mathrm{Br} \mathrm{J}$ Gen Pract 1997; 47(417): 211-215.

9. Diekstra RF, van Egmond M. Suicide and attempted suicide in general practice, 1979-1986. Acta Psychiatr Scand 1989; 79(3): 268-275.

10. Isometsä ET, Heikkinen ME, Marttunen MJ, et al. The last appointment before suicide: is suicidal intent communicated? Am J Psychiatry 1995; 152(6): 919-922.

11. Appleby L, Kapur N, Shaw J, et al. Avoidable deaths. Five year report of the National Confidential Inquiry into suicide and homicide by people with mental illness. Manchester: University of Manchester, 2006.

12. Appleby L, Shaw J, Sherratt J, et al. Safety first. Five year report of the National Confidential Inquiry into suicide and homicide by people with mental illness. London: Department of Health; 2001.

13. Meehan J, Kapur N, Hunt IM, et al. Suicide in mental health in-patients within 3 months of discharge. National clinical survey. Br J Psychiatry 2006; 188: 129-134

14. Office for National Statistics. Population estimates for UK, England, Wales, Scotland and Northern Ireland. Mid-2006 population estimates for UK, England, Wales, Scotland and Northern Ireland. London: ONS: 2007 
15. Appleby L, Cooper J, Amos T, Faragher B. Psychological autopsy study of suicides by people aged under 35. Br J Psychiatry 1999; 175: 168-174.

16. Cooper J, Appleby L, Amos T. Life events preceding suicide by young people. Soc Psychiatry Psychiatr Epidemiol 2002; 37(6): 271-275.

17. Steel RGD, Torrie JH. Principles and procedures of statistics: a biometrical approach. 2nd edn. New York: McGraw-Hill, 1986.

18. Hawton K, Harriss L, Hall S, et al. Deliberate self-harm in Oxford, 1990-2000: a time of change in patient characteristics. Psychol Med 2003; 33(6): 987-995.

19. Gunnell D, Bennewith O, Peters TJ, et al. Do patients who self-harm consult their general practitioner soon after hospital discharge? A cohort study. Soc Psychiatry Psychiatr Epidemiol 2002; 37(12): 599-602.

20. Mistry H, Buxton M, Longworth L, et al. Comparison of general practitioner records and patient self-report questionnaires for estimation of costs. Eur J Health Econ 2005; 6(3): 261-266.

21. Jordan K, Porcheret M, Croft P. Quality of morbidity coding in general practice computerized medical records: a systematic review. Fam Pract 2004; 21(4):396-412.

22. Office for National Statistics. General household survey overview 2007. London: ONS; 2009. http://www.statistics.gov.uk/ statbase/prep/5756.asp (accessed 21 Sep 2009).

23. Foster T, Gillespie K, McClelland R. Mental disorders and suicide in Northern Ireland. Br J Psychiatry 1997; 170: 447-452.

24. Macdonald A. 'Suicide prevention' by GPs? Br J Psychiatry 1992; 161:

25. Biddle L, Donovan JL, Gunnell D, Sharp D. Young adults' perceptions of GPs as a help source for mental distress: a qualitative study. $\mathrm{Br} \mathrm{J} \mathrm{Gen}$ Pract 2006; 56(533): 924-931.

26. Telford R, Hutchinson A, Jones R, et al. Obstacles to effective treatmen of depression: a general practice perspective. Fam Pract 2002; 19(1) $45-52$.

27. Carlisle D. NHS discharge planning: lost for words. Health Serv J 2009;
119(6141): 18-20.

28. Appleby L, Shaw J, Amos T, et al. Suicide within 12 months of contact with mental health services: national clinical survey. BMJ 1999; 318(7193): 1235-1239.

29. Appleby L, Amos T, Doyle U, et al. General practitioners and young suicides: a preventative role for primary care. Br J Psychiatry 1996; 168(3): 330-333.

30. Milton J, Ferguson B, Mills T. Risk assessment and suicide prevention in primary care. Crisis 1999; 20(4): 171-177.

31. Owens C, Lloyd KR, Campbell J. Access to health care prior to suicide: findings from a psychological autopsy study. Br J Gen Pract 2004; 54(501): 279-281.

32. Lake CR. How academic psychiatry can better prepare students for their future patients. Part I: the failure to recognize depression and risk for suicide in primary care; problem identification, responsibility and solutions. Behav Med 2008; 34(3): 95-100.

33. Lake CR. How academic psychiatry can better prepare students for their future patients. Part II: a course in ultra-brief initial diagnostic screening suitable for future primary care physicians. Behav Med 2008; 34(3): 101-116.

34. Hawgood JL, Krysinska KE, Ide N, De Leo D. Is suicide prevention properly taught in medical schools? Med Teach 2008; 30(3): 287-295.

35. Mann JJ, Apter A, Bertolote J, et al. Suicide prevention strategies: a systematic review. JAMA 2005; 294(16): 2064-2074.

36. Beautrais A, Fergusson D, Coggan C, et al. Effective strategies for suicide prevention in New Zealand: a review of the evidence. NZ Med J 2007; 120(1251): U2459.

37. Gilbody S, Whitty P, Grimshaw J, Thomas R. Educational and organisational interventions to improve the management of depression in primary care: a systematic review. JAMA 2003; 289(23): 3145-3151.

38. Richards DA, Lankshear AJ, Fletcher J, et al. Developing a UK protocol for collaborative care: a qualitative study. Gen Hosp Psychiatry 2006; 28(4): 296-305 